\title{
Efficacy of Intensive Phototherapy in Management of Neonatal Hyperbilirubinemia in Neonatal Unit of Assiut University Children Hospital
}

\author{
Abdelazeem $\mathrm{KS}^{*}$, Soliman AA and Askar EAA
}

Pediatrics Department, Faculty of Medicine, Assiut University, Egypt

*Corresponding author: Abdelazeem KS, Pediatrics Department, Faculty of Medicine, Assiut University, Egypt, Tel: 01097983695; E-mail: khaleds2586@gmail.com Received date: December 01, 2017; Accepted date: December 15, 2017; Published date: December 22, 2017

Copyright: (C) 2017 Abdelazeem KS, et al. This is an open-access article distributed under the terms of the Creative Commons Attribution License, which permits unrestricted use, distribution, and reproduction in any medium, provided the original author and source are credited.

\begin{abstract}
Objective: To assess the effectiveness of intensive phototherapy in comparison with conventional phototherapy in reducing the need for exchange transfusion and the duration of phototherapy for management of neonatal hyperbilirubinemia in Neonatal Unit of Assiut University Children Hospital.
\end{abstract}

Methods: The prospective study was conducted from March 2016 to February 2017 and comprised neonates with indirect hyperbilirubinaemia near the level of ECT who were admitted to the Neonatal Unit of Assiut University Children Hospital and treated with intensive phototherapy (group 1). These neonates were compared with a historical retrospective group who had been treated with conventional therapy from March 2012 to February 2013 (group 2). Both groups were subjected to complete clinical evaluation and laboratory investigations.

Results: The use of intensive phototherapy in the treatment of indirect pathological hyperbilirubinaemia is very effective in lowering total serum Bilirubin when its level is within $2-3 \mathrm{mg} / \mathrm{dl}(34-50 \mathrm{umol} / \mathrm{l})$ of the exchange transfusion level and it has succeeded in reducing the frequency of exchange transfusion with its hazards and serious complications. It has also succeeded in reducing the duration of phototherapy and subsequently the duration of hospital stay and economic burden.

Conclusion: The use of intensive phototherapy in the treatment of indirect pathological hyperbilirubinaemia is as effective as exchange transfusion in lowering Total Serum Bilirubin when its level is within $2-3 \mathrm{mg} / \mathrm{dl}(34-51 \mu \mathrm{mol} / \mathrm{l})$ of the exchange level and it is effective in reducing needs for exchange transfusion and duration of phototherapy.

Keywords Neonatal jaundice; Conventional phototherapy; Intenive phototherapy; Exchange transfusion; Kernicterus

\section{Introduction}

Hyperbilirubinemia is a common and considered a benign problem in neonates. Jaundice is observed during the 1 st wk after birth in approximately $60 \%$ of term infants and $80 \%$ of preterm infants. The yellow color usually results from the accumulation of unconjugated, nonpolar, lipid-soluble bilirubin pigment in the skin. Although bilirubin may have a physiologic role as an antioxidant, elevations of indirect, unconjugated bilirubin are potentially neurotoxic. Even though the conjugated form is not neurotoxic, direct hyperbilirubinemia indicates a potentially serious hepatic disorders or a systemic illness [1].

Regardless of the cause, the goal of therapy is to prevent neurotoxicity related to indirect-reacting bilirubin while not causing undue harm. Phototherapy and, if it is unsuccessful, exchange transfusion remain the primary treatment modalities used to keep the maximal total serum bilirubin below pathologic levels [2]

Maximal intensive phototherapy should be used when indirect bilirubin levels approach certain levels. Such therapy includes using "special blue" fluorescent tubes, placing the lamps within $15-20 \mathrm{~cm}$ of the infant, and putting a fiberoptic phototherapy blanket under the infant's back to increase the exposed surface area. The use of phototherapy has decreased the need for exchange transfusion in term and preterm infants with pathological jaundice [1].

\section{Patients and Methods}

The study consisted of two groups; one including neonates with indirect hyperbilirubinaemia near the level of ECT who were admitted to the Neonatal Unit of Assiut University Children Hospital and treated with intensive phototherapy from March 2016 to February 2017 (group 1) and the other included a historical retrospective group who had been treated with conventional therapy from March 2012 to February 2013 (group 2).

Neonates with Direct hyperbilirubinemia, mixed hyperbilirubinemia and Sepsis were excluded.

Detailed history, examination and investigations were taken from both groups.

\section{Statistical Analysis}

The data were tested for normality using the Anderson-Darling test and for homogeneity variances prior to further statistical analysis. Categorical variables were described by number and percent $(\mathrm{N}, \%)$, where continuous variables described by mean and standard deviation 
Citation: Abdelazeem KS, Soliman AA, Askar EAA (2017) Efficacy of Intensive Phototherapy in Management of Neonatal Hyperbilirubinemia in Neonatal Unit of Assiut University Children Hospital. J Neonatal Biol 6: 266. doi:10.4172/2167-0897.1000266

Page 2 of 4

(Mean, SD). Chi-square test and fisher exact test used to compare between categorical variables where compare between continuous variables by unpaired t-test. A two-tailed $\mathrm{p}<0.05$ was considered statistically significant. All analyses were performed with the IBM SPSS 20.0 software.

\section{The role of care manager}

Proper care enhances the effectiveness of phototherapy and decrease complications. Caregiver responsibilities include maximizing skin exposure, providing eye protection and eye care, careful attention to thermoregulation, maintaining adequate hydration, promoting elimination.

\section{History}

History taken included perinatal history with special emphasis on maternal illness, mode of delivery, natal history including cyanosis or convulsion, gestational age, weight, gender and age at admission.

\section{Clinical examination}

It was done with special emphasis on vital signs, anthropometric measures, presence of cephalohaematoma and neurological examination. New-borns under study were subjected to management according to American Academy of Pediatrics Guidelines for management of neonatal hyperbilirubinemia.

\section{Investigation}

Total and direct serum bilirubin on admission and 6 hours after exposure to phototherapy, Complete blood count (CBC), Reticulocyte count, Blood group and $\mathrm{Rh}$ of mother and neonate were estimated for all cases on admission

The data were tested for normality using the Anderson-Darling test and for homogeneity variances prior to further statistical analysis. Categorical variables were described by number and percent $(\mathrm{N}, \%)$, where continuous variables described by mean and standard deviation (Mean, SD). Chi-square test and fisher exact test used to compare between categorical variables where compare between continuous variables by unpaired $\mathrm{t}$-test. A two-tailed $\mathrm{p}<0.05$ was considered statistically significant. All analyses were performed with the IBM SPSS 20.0 software.

\section{Results}

\begin{tabular}{|l|l|l|}
\hline Gestational age (weeks) & Group 1 & Group 2 \\
\hline Mean \pm 2SD & $36.6 \pm 1.6$ & $37 \pm 1.78$ \\
\hline Full term & 38 & 42 \\
\hline Preterm & 12 & 8 \\
\hline Mode of delivery & & \\
\hline CS & $26(52 \%)$ & $27(54 \%)$ \\
\hline VD & $24(48 \%)$ & $23(46 \%)$ \\
\hline Sex & & $28(56 \%)$ \\
\hline Males & $26(52 \%)$ & $22(44 \%)$ \\
\hline Females & $24(48 \%)$ & \\
\hline
\end{tabular}

\begin{tabular}{|l|l|l|}
\hline Birth weight $(\mathbf{g})$ & & \\
\hline Mean \pm 2SD & $3000.0 \pm 360$ & $2970.0 \pm 280$ \\
\hline Age on admission (days) & & \\
\hline Range & $1-3$ days & $1-4$ days \\
\hline Mean \pm SD & $2 \pm 0.5$ & $2.3 \pm 1.1$ \\
\hline
\end{tabular}

Table 1: Demographic data.

\begin{tabular}{|c|c|c|c|}
\hline Risk category & Group 1 & Group 2 & \multicolumn{1}{l|}{ P. Value } \\
\hline High risk & $28(56 \%)$ & $31(62 \%)$ & NS \\
\hline Intermediate risk & $12(24 \%)$ & $9(18 \%)$ & NS \\
\hline Low risk & $10(20 \%)$ & $10(20 \%)$ & NS \\
\hline
\end{tabular}

Table 2: Risk categories.

\begin{tabular}{|l|l|l|l|}
\hline Rate of S.Bilirubin decline & Group 1 & Group 2 & P. Value \\
\hline Mean $\pm 2 \mathrm{SD}$ & $\begin{array}{l}0.56 \pm 0.12 \\
\mathrm{mg} / \mathrm{dl} / \mathrm{h}\end{array}$ & $\begin{array}{l}0.17 \pm 0.05 \\
\mathrm{mg} / \mathrm{dl} / \mathrm{hr}\end{array}$ & $<0.001^{* *}$ \\
\hline
\end{tabular}

Table 3: Rate of serum bilirubin decline 6 hours after intensive phototherapy.

\begin{tabular}{|l|l|l|l|}
\hline $\begin{array}{l}\text { Duration (days) of } \\
\text { phototherapy }\end{array}$ & Group 1 & Group 2 & P. Value \\
\hline Mean \pm 2SD & $2.5 \pm 1.5$ days & $2.5 \pm 1.5$ days & $<0.001^{* *}$ \\
\hline
\end{tabular}

Table 4: Duration of phototherapy.

\begin{tabular}{|c|c|c|c|}
\hline $\begin{array}{c}\text { Exchange } \\
\text { transfusion }\end{array}$ & Group 1 & Group 2 & P. value \\
\hline Number & 16 & 31 & \multirow{2}{*}{$0.003^{\text {** }}$} \\
\hline$\%$ & $32 \%$ & $62 \%$ & \\
\hline
\end{tabular}

Table 5: Rate of exchange transfusion.

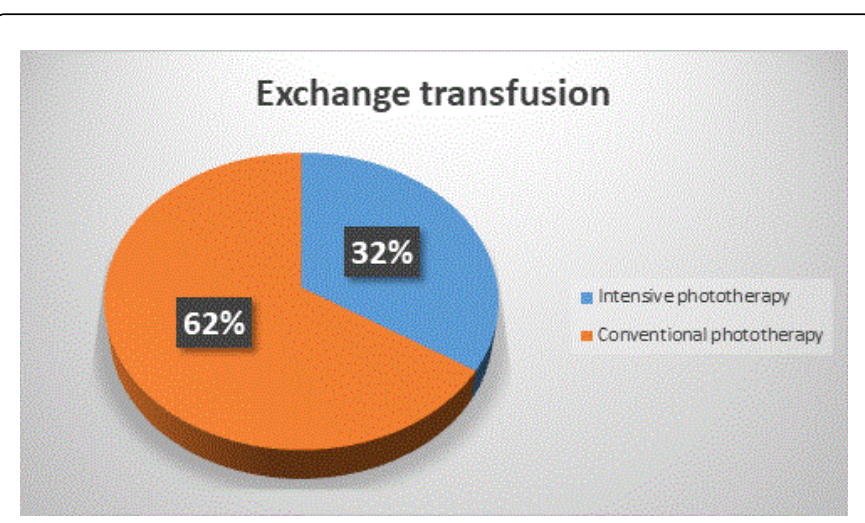

Figure 1: Rate of exchange transfusion. 


\begin{tabular}{|c|c|c|}
\hline $\begin{array}{c}\text { Complications of intensive } \\
\text { phototherapy }\end{array}$ & Number & $\%$ \\
\hline Skin rash & 14 & 28 \\
\hline Rebound & 6 & 12 \\
\hline Dehydration & 3 & 6 \\
\hline
\end{tabular}

Table 6: Complications of intensive phototherapy.

\section{Discussion}

Neonatal jaundice is common and generally not harmful, very high TSB levels can cause central nervous system long term morbidities and mortalities. So aggressive and early treatment is mandatory

Intensive phototherapy is a novel neonatal phototherapy device and our study evaluated its effectiveness on 50 newborns with severe indirect hyperbilirubinaemia (group 1) and compared it to a historical control group consisting of 50 neonates treated with conventional phototherapy retrospectively (group 2). Both groups were comparable regarding all of the pre-treatment demographic, clinical and laboratory parameters.

Regarding gestational age, sex, mode of delivery, birth weight, and age on admission there was no statistically significant difference between the two groups as shown in Table 1 .

Regarding baseline laboratory data the study showed that total serum bilirubin level ranged from $18-30 \mathrm{mg} / \mathrm{dl}$ with mean $23 \pm 3.71$ for group [1] and for group [2], it ranged from $20-30 \mathrm{mg} / \mathrm{dl}$ with mean $23.9 \pm 2.9$. Edris et al. [3] reported that the mean of total serum bilirubin at admission $26.2 \mathrm{mg} / \mathrm{dl}$. Boonyarittipong et al. [4] reported that that initial bilirubin level was $14.8+1.7 \mathrm{mg} / \mathrm{dl}$ for Single-Surface Intensive Phototherapy group (SSIPT) and $15.7+1.7 \mathrm{mg} / \mathrm{dl}$ for DoubleSurface Intensive Phototherapy group (DsIPT). Karadag et al. [5] showed that Admission TSB level $(\mathrm{mg} / \mathrm{dL})$ was $20.2 \pm 1.3$ for the intensive phototherapy group and $19.6 \pm 1.5$ for the conventional phototherapy group.

It was found that $\mathrm{ABO}$ was more common than $\mathrm{RH}$ incompatibility in both groups and was associated more commonly with blood groups $\mathrm{A}$ and $\mathrm{B}$.

According to American Academy of Pediatrics guidelines our studied cases were classified into high, intermediate and low risk categories, in group [1] it was found that $28(56 \%)$ cases in the high risk category; 12 cases (24\%) in the intermediate risk category and 10 cases $(20 \%)$ in the low risk category. In group [2] it was found that 31 cases $(62 \%)$ were in the high risk category; 9 cases $(18 \%)$ in the intermediate risk category and 10 cases $(20 \%)$ in the low risk category as shown in Table 2.

The Total Serum Bilirubin decline rate $6 \mathrm{~h}$ after admission was significantly more in intensive phototherapy group than the controls $(\mathrm{p}<0.01)$. The mean of the rate of serum bilirubin decline in group [1] was $0.56 \pm 0.12 \mathrm{mg} / \mathrm{dl} / \mathrm{h}$ while in group [2] was $0.17 \pm 0.05 \mathrm{mg} / \mathrm{dl} / \mathrm{h}$ with p-value showed statistically significant difference between the two groups as shown in Table 3. Sarici et al. [6] demonstrated the efficacy of double phototherapy using standard phototherapy unit consisted of five special blue lamps combined with fiberoptic phototherapy pad beneath the infant's body and the reduction rate of bilirubin was more than that in single phototherapy probably due to the higher irradiance of the authors' phototherapy units. Thaithumyanon and
Visutiratmanee [7] reported that the reduction of bilirubin in the first day was $3.4+2.0 \mathrm{mg} / \mathrm{dl}$ using double surface phototherapy which was more than that in single conventional phototherapy. However, Nuntnarumit and Naka [8] reported the reduction of bilirubin was $0.22 \mathrm{mg} / \mathrm{dl} / \mathrm{h}$ resulted from using adapted-double phototherapy. The differences of bilirubin reduction in the present study from the previous studies were probably due to the difference of the irradiance of the light, type of light sources, the instruments measuring the irradiance and bilirubin concentration and the type of feeding.

Centre National de Reference en Haemobiologie Perinatale studied the effect of intensive phototherapy on blood levels of TSB over $20 \mathrm{~h}$ treatment in jaundiced newborn, revealing that this device allows an average decrease in TSB levels of $15 \%, 26 \%$ and $37 \%$ at hours 4,10 and 20 exposure, respectively.

Intensive phototherapy shortens the duration of hospital stay and in turn a shorter duration of hospitalisation. This would also mean considerably less separation from the mother and less interruption of breastfeeding and economic burden.

The current study showed the mean of duration of phototherapy in group [1] was $2.5 \pm 1.5$ days while in group [2] it was found that the mean of the duration of phototherapy was $4.0 \pm 1.4$ days as shown in Table 4. These results were consistent with the previous study of Edris et al. [3] which reported that the mean of duration of phototherapy for the group treated with intensive phototherapy was 2.7 days and the mean for the conventional phototherapy group was 4.2 days.

Regarding the need for exchange transfusion (ECT) in intensive phototherapy group, only $16(32 \%)$ out of 50 cases needed ECT and this was much lower than the conventional group 31 (62\%) out of 50 cases as shown in Table 5 and illustrated in Figure 1. Edris et al. [3] reported that only $19(10.4 \%)$ out of 188 cases required ECT and this was much lower than the control group 130 (73.4\%) out of 177 cases. De Carvalho et al. [9] showed that the use of intensive phototherapy was effective in treating newborn infants admitted with severe nonhaemolytic hyperbilirubinaemia $(\mathrm{TSB}<20 \mathrm{mg} / \mathrm{dL}$ ) and none of the patients required ECT. El-feky et al. [10] reported that concerning the need for ECT in intensive phototherapy group, only 16 (16.0\%) out of 100 cases required ECT and this was much lower than the conventional phototherapy group (66 (66.0\%) out of 100 cases).

It was found that out of 50 cases, 6 (12\%) cases needed phototherapy again and cases of them were preterms ( $>35$ weeks) with their birth weight $(>2000 \mathrm{~g})$. These results were comparable with that of Kaplan et al. [11] who documented that a total of $30(13.3 \%)$ neonates developed rebound. Kaplan et al. [11] reported that aetiological risk factors included positive direct Coombs test and gestational age $<37$ weeks. Bansal et al. [12] reported that Postphototherapy bilirubin estimation was done in 232 neonates. A total of 17 (7.3\%) neonates developed bilirubin rebound.

Skin rash was found in $14(28 \%)$ cases treated with intensive phototherapy. Dehydration was found in 3 cases (6\%) and needed frequent feeding or intravenous (Table 6).

\section{Study Limitations}

The sample size being small that is only 100 newborns that limited the scope of research.

Time constraints put boundaries to sample area and hence limited the extent of the study. 
Citation: Abdelazeem KS, Soliman AA, Askar EAA (2017) Efficacy of Intensive Phototherapy in Management of Neonatal Hyperbilirubinemia in Neonatal Unit of Assiut University Children Hospital. J Neonatal Biol 6: 266. doi:10.4172/2167-0897.1000266

Page 4 of 4

The study was confined to the city of Assiut.

Post-hoc power analysis was done on rate of exchange transfusion in both groups and it was $86.4 \%$.

\section{Conclusion}

The use of intensive phototherapy in the management of pathological hyperbilirubinaemia is very effective in lowering total serum Bilirubin when its level is within $2-3 \mathrm{mg} / \mathrm{dl}(34-50 \mu \mathrm{mol} / \mathrm{l})$ of the exchange transfusion level and in reducing the use of the invasive maneuver of exchange transfusion with its serious neurological complications. It has also succeeded in reducing the duration of phototherapy and subsequently the duration of hospital stay and economic burden.

\section{Recommendations}

1. It is recommended to apply intensive phototherapy for treatment of indirect hyperbilirubinemia in every neonatal unit of our central and general hospitals because it helps to shorten the hospital stay and reduce the need for exchange transfusion and the economic costs.

2. Coombs test should be done for all cases of suspected neonatal hemolytic jaundice.

3. Neonatologists should attend all deliveries that are at high risk for developing neonatal jaundice.

4. Advise parents and carers to seek urgent advice from a healthcare professional if their baby becomes jaundiced especially within the first $24 \mathrm{~h}$ of life.

5. Keep eyes on babies with hemolytic jaundice to avoid post phototherapy rebound.

\section{References}

1. Ambalavanan N, Carlo WA. Jaundice and hyperbilirubinemia in the newborn. In: Nelson text book of pediatrics (20th edn), Kliegman RM (edtr,), Elsevier Inc., p: 871.
2. Maisels MJ, McDonagh AD (2008) Phototherapy for neonatal jaundice. $\mathrm{N}$ Engl J Med 358: 920-928.

3. Edris AA, Ghany EA, Razek AR, Zahran AM (2014) The role of intensive phototherapy in decreasing the need for exchange transfusion in neonatal jaundice. J Pak Med Assoc 1: 5-8.

4. Boonyarittipong P, Kriangburapa W, Booranavanich K (2008) Effectiveness of double-surface intensive phototherapy versus singlesurface intensive phototherapy for neonatal hyperbilirubinemia. J Med Assoc Thai 91: 50-55.

5. Karadag A, Yesilyurt A, Unal S, Keskin I, Demirin H, et al. (2009) A chromosomal effect study of intensive phototherapy versus conventional phototherapy in newborns with jaundice. Mutat Res 676: 17-20.

6. Sarici SU, Alpay F, Unay B, Ozcan O, Gokcay E (2000) Double versus single phototherapy in term newborns with significant hyperbilirubinemia. J Trop Pediatr 46: 36-9.

7. Thaithumyanon P, Visutiratmanee C (2002) Double phototherapy in jaundiced term infants with hemolysis. J Med Assoc Thai 85: 1176-1181.

8. Nuntnarumit P, Naka C (2002) Comparison of the effectiveness between the adapted-double phototherapy versus conventional-single phototherapy. J Med Assoc Thai 85: S1159-S1166.

9. De Carvalho M, Mochdece CC, Sa CA, Moreira ME (2011) Highintensity phototherapy for the treatment of severe non-haemolytic neonatal hyperbilirubinemia. Acta Paediatr 100: 620-623.

10. El-feky OA, El-Khashab AM, Sobeih AA, El-Hameed MGA (2016) The role of intensive phototherapy device in treatment of neonatal jaundice. Med J Cairo Univ 84: 271-275.

11. Kaplan M, Kaplan E, Hammerman C (2006) Post phototherapy neonatal bilirubin rebound: A potential cause of significant hyperbilirubinemia. Arch Dis Child 91: 31-4.

12. Bansal A, Jain S, Parmar VR, Chawla D (2010) Bilirubin rebound after intensive phototherapy for neonatal jaundice. Indian Pediatr 47: 607. 